\title{
Massive Subcutaneous Emphysema and Intraoperative Hyper- carbia after Transanal Endoscopic Microsurgery (TEMS)
}

\author{
Abhishek Singh", Apala Roy Chowdhury, Ameya Pappu and Puneet khanna \\ Department of Anesthesiology, All India Institute of Medical Sciences, India

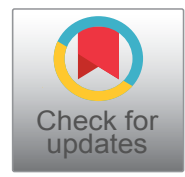

*Corresponding author: Dr. Abhishek Singh, Senior Resident, Department of Anesthesiology, Pain Medicine and Critical Care, All India Institute of Medical Sciences, New Delhi, Pin -110029, India, Tel: 918287652624

\begin{abstract}
Transanal endoscopic microsurgery (TEMS) is minimally invasive, safe and highly effective treatment modality for resecting small rectal lesion like adenomas, early stage carcinoma and strictures. We describe an unusual case of massive subcutaneous emphysema and hypercarbia secondary to TEMS leading to ventilatory difficulty and post-operative mechanical ventilation. Extra peritoneal insufflation of $\mathrm{CO}_{2}$ at high pressure, for prolonged duration and extent of tissue dissection are some of the predisposing factor leading to rare but life threatening respiratory complications. intra operative management should consist of changing from nitrous oxide if we are using it to air and oxygen, expediting the surgery, reducing the insufflation pressure and careful extubation while postoperatively conservative management should be considered with close monitoring of the patient for timely intervention if condition of the patient deteriorates.
\end{abstract}

\section{Abbreviation}

TEMS: Transanal Endoscopic Microsurgery; ASA: American Society of Anesthesiologist; PEEP: Positive End Expiratory Pressure; $\mathrm{FiO}_{2}$ : Fraction of Inspired Oxygen; $\mathrm{ETCO}_{2}-$ : End Tidal Carbondiaoxide

\section{Introduction}

Carcinoma of rectum is one of the most common cancer of gastrointestinal tract in adults leading to morbidity and mortality worldwide. Highly invasive form of rectal cancer is preceded by development of adenomas. Among adenomas tubullovillous and villous adenomas have high incidence of transformation to invasive colorectal cancer [1].

Transanal endoscopic microsurgery (TEM) is a minimally technique which is developed for the resection of benign rectal lesions. Transanal endoscopic microsurgery was introduced in 1983. It has emerged as one of the safer, highly effective and minimally invasive method of resecting rectal lesions like adenoma, early stage carcinoma and stricture [2]. TEM has the advantage of good visualization, better exposure and allowing use of both hands during procedure resulting in more precise excision of lesions as compared to previous used technique. One of the major benefit of using TEM is the significantly lower morbidity and mortality as compared to traditional technique of treating rectal lesions like abdominoperineal resection and low anterior resection [3]. Quality of life after TEM is better because functional integrity of anal sphincter is preserved and damage to autonomic nerves is averted. Intra operative and postoperative complication associated with TEM are rare and include bleeding, perforation, incontinence and rectal stricture [4].

Our case report is unique because it shows one of the potentially life threatening but rare complication of TEMS that is massive intraperitoneal, subcutaneous emphysema and hypercarbia necessitating post-operative ventilatory support and monitoring in intensive care unit.

\section{Case Description}

A 77 year old man presented with three episodes of rectal bleeding. Colonoscopy revealed several sessile polyp throughout the length of colon. There was also presence of a one large polyp measuring $4 \mathrm{~cm}$ in diameter located at approximately $10 \mathrm{~cm}$ from the anal verge. Pathology report showed tubular adenoma with high

Citation: Singh A, Chowdhury AR, Pappu A, Khanna P (2020) Massive Subcutaneous Emphysema and Intraoperative Hypercarbia after Transanal Endoscopic Microsurgery (TEMS). Int J Anesthetic Anesthesiol 7:107. doi.org/10.23937/2377-4630/1410107

Accepted: May 04, 2020: Published: May 06, 2020

Copyright: (C) 2020 Singh A, et al. This is an open-access article distributed under the terms of the Creative Commons Attribution License, which permits unrestricted use, distribution, and reproduction in any medium, provided the original author and source are credited. 
grade dysplasia but CT scan of abdomen, pelvic MRI and rectal ultrasonography did not show any sign of invasive growth, pathologic lymph nodes or systemic spread. Since the lesion was small and patient was not willing to consent to a more invasive procedure such as abdominal perineal resection, so TEMS was planned. The patient was ASA physical status class 2 with history of hypertension well controlled with metoprolol and past history of head injury for which he was on phenytoin for last 10 years. His pulmonary function was within normal limit with no history of smoking and chest disease.

After pre oxygenation, General anesthesia was induced with fentanyl, Propofol and atracurium and endotracheal tube was placed. Volume controlled ventilation was used during the surgery with peak airway pressures was between 15 to $17 \mathrm{~cm}$ of $\mathrm{H}_{2} \mathrm{O}$ without PEEP. Anesthesia was maintained using oxygen, nitrous oxide and desflurane. Morphine, paracetamol and ketorolac was given for intraoperative analgesia.

Patient was placed in lithotomy position with head tilted slightly downwards. Carbon dioxide was insufflated at rate of $6 \mathrm{~L} / \mathrm{min}$ while maintaining intraluminal pressure below $12 \mathrm{~mm}$ of $\mathrm{Hg}$.

Initial course of the surgery was uneventful but after 2 hours there was sudden rise in end tidal $\mathrm{CO}_{2}$ which coincided with rise in peak airway pressure from 17 to 28 $\mathrm{cm}$ of $\mathrm{H}_{2} \mathrm{O}$ and fall in oxygen saturation from $99 \%$ to $94 \%$ despite no change in patient position or tidal volume. On auscultation, chest sounds was within normal limit. Patient's core body temperature was normal and hemodynamics was stable. Minute ventilation was increased, $\mathrm{FiO}_{2}$ was increased from $30 \%$ before incident to $100 \%$ and Nitrous oxide was replaced with air as there was high suspicion of undetected pneumothorax. But the issue did not resolved with increased minute ventilation and atracurium was given with the hope that adequate muscle relaxation might improve ventilation and result in reduction of $\mathrm{EtCO}_{2}$ and peak airway pressure which proved futile. Physical examination revealed massive subcutaneous emphysema involving the neck, anterior abdominal wall, and scrotum extending up to both thighs. No signs of peritoneal perforation was noted during the procedure and bladder drainage was clear. It was decided to shift the patient to intensive care unit as even after completion of procedure, patient showed saturation of $95 \%, \mathrm{ETCO}_{2}$ of $48 \mathrm{~mm}$ of $\mathrm{Hg}$ and peak airway pressure of $25 \mathrm{~cm}$ of water.

Neuromuscular paralysis was reversed with neostigmine and glycopyrrolate but patient was not extubated and shifted to intensive care unit. Immediate chest $X$ ray was done which confirmed the presence of subcutaneous emphysema but there was no sign of pneumotho$\operatorname{rax}$ (Figure 1). Arterial blood gas analysis at $\mathrm{FiO}_{2}$ of $100 \%$ and volume controlled ventilation showed respiratory acidosis.

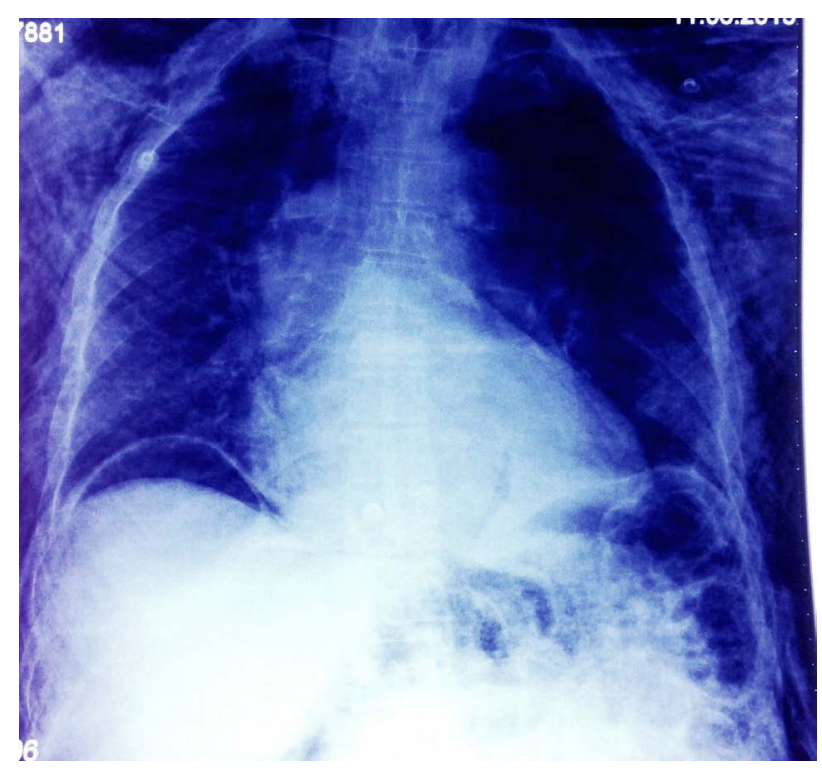

Figure 1: Showing free gas under the diaphragm.

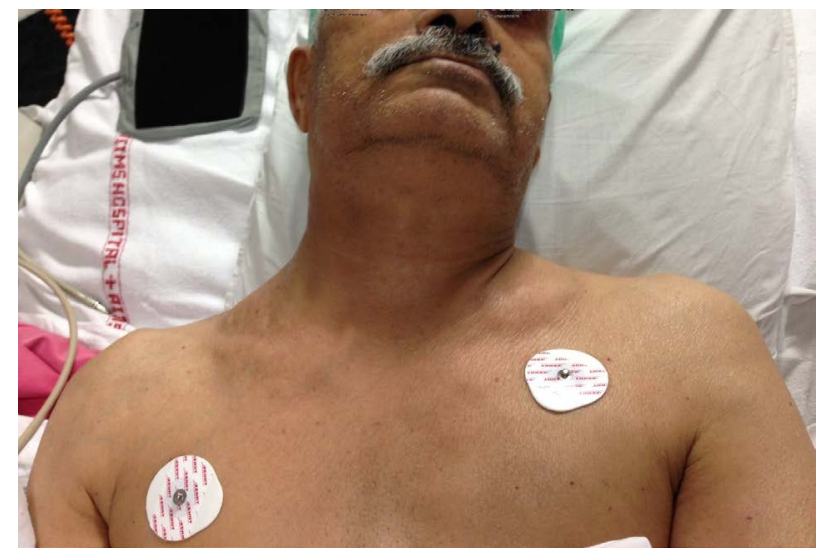

Figure 2: Showing subcutaneous emphysema.

\section{Course in ICU}

Day 1: Mechanical ventilation using pressure support ventilation was used. Repeat chest $x$-ray showed free gas under the diaphragm but there was no sign of guarding or rigidity. Subcutaneous emphysema was still present (Figure 2).

Day 2: Patient was extubated in the evening and subcutaneous emphysema started resolving.

Day 3: Subcutaneous emphysema resolved up to $90 \%$.

Day 4 and Day 5: Patient was comfortable, taking orally, passed stool and flatus.

Day 6: The patient was transferred to ward care.

Day 7: Patient was discharged and asked to follow up as outpatient in surgical outpatient department.

\section{Investigation}

Chest $\mathrm{x}$ ray and arterial blood gas analysis was done twice daily so that any deterioration in the clinical condition of the patient can be diagnosed promptly. 


\section{Outcome and follow up}

The subcutaneous emphysema resolved on day 5 and patient was discharged on day 7 with stool softener, antibiotics and proton pump inhibitor.

Patient was asked to continue taking phenytoin and metoprolol as advised before.

Routine investigation on subsequent visit showed no sign of residual tumor and now patient is on regular follow up.

\section{Discussion}

This case describes the effect of intraoperative hypercarbia and subcutaneous emphysema during TEMS leading to delayed extubation and extended stay in the ICU. It is a well-known fact that we should increase minute ventilation in order to maintain normocapnia during laparoscopic surgery but no such recommendation is available for TEM surgery. It has been reported that intraperitoneal insufflation of $\mathrm{CO}_{2}$ leads to subcutaneous emphysema in $3 \%$ of the cases during laparoscopy [5].

TEMS though reduces morbidity and mortality associated with APR and permanent stoma but still it is associated with various complication. Some are due to patient positioning while others are due to prolonged surgery. Some rare complications are also associated with it like development of massive subcutaneous emphysema and hypercapnia leading to ventilator failure.

However, the incidence of subcutaneous emphysema with TEM is extremely low [6]. Mechanism are raised insufflation pressure, duration of insufflation, extra peritoneal approach and extent of tissue dissection. The development of subcutaneous emphysema is likely due to tracking of gas under tension along the surgically opened tissue planes. A gas flow of at least 6 liters/minute has been recommended to maintain in- tra rectal pressure of $12-15 \mathrm{~mm}$ of $\mathrm{Hg}$. We recommend the clinicians to monitor insufflation flow and intrarectal pressure continuously. The lithotomy position along with spread of carbon dioxide to loin, groin, anterior abdominal wall and thigh hindered detection of surgical emphysema in our patient. We suggest detailed examination of patients at unusual site for surgical emphysema if very high level of $\mathrm{EtCO}_{2}$ or $\mathrm{PaCO}_{2}$ are noted during TEMS.

Blair showed that insufflation of carbon dioxide into subcutaneous fat of anterior abdominal wall of anesthetized pigs having fixed minute ventilation resulted in increased arterial carbon dioxide concentration and fall in blood pH for long duration [7]. He suggested that patient with similar condition should undergo repeated testing of arterial carbon dioxide and remain in the recovery room for longer time. Our case demonstrate the life threatening complication post TEMS by a mechanism similar to Blair's model.

The potential differential diagnoses can be Spontaneous pneumothorax, acute respiratory failure, pulmonary embolus and intraperitoneal perforation. Various methods of prevention and differential diagnoses are mentioned in Table 1.

"Kerr and Mills" in 2001 reported a case of intraoperative and postoperative hypercapnia leading to delayed respiratory failure secondary to TEMS with moderate degree of subcutaneous emphysema. They told that a patient with arterial hypercapnia and subcutaneous emphysema should be observed for prolonged period with regular blood gas analysis to allow timely intervention [8].

Franken, et al. in 2012 described 2 cases of free intra-abdominal air without perforation after TEMS. In both cases diagnostic laparoscopy showed no peritoneal breech and both patient were managed conserva-

Table 1: Prevention strategies and differential diagnoses for subcutaneous emphysema.

\begin{tabular}{|c|c|}
\hline Differential diagnoses for perioperative hypercarbia & Preventive strategy \\
\hline Spontaneous pneumothorax & $\begin{array}{l}\text { 1- Detailed history and Pre-anesthetic check up } \\
\text { 2- Preoperative pulmonary function test } \\
\text { 3- Lung protective ventilatory strategy } \\
\text { 4- Careful extubation }\end{array}$ \\
\hline Acute respiratory failure & $\begin{array}{l}\text { 1- Judicious use of opioids } \\
\text { 2- Non opioid analgesia } \\
\text { 3- Proper monitoring of respiratory mechanics }\end{array}$ \\
\hline Intra peritoneal perforation & $\begin{array}{l}\text { 1- Monitoring for clinical sign and symptom } \\
\text { 2- Low threshold for suspicion }\end{array}$ \\
\hline Pulmonary embolism & $\begin{array}{l}\text { 1- Assessing risk factors in Pre-anesthetic checkup } \\
\text { 2- Detailed history } \\
\text { 3- Review of medical records } \\
\text { 4- Close intraoperative monitoring }\end{array}$ \\
\hline
\end{tabular}


tively. However they suggested that close monitoring of patient is necessary, so that conservative management can be replaced by surgery if the patient's condition deteriorates [9].

Aninda Chandra, et al. in 2014 reported the first case of massive subcutaneous emphysema with hypercarbia leading to ventilator difficulty. Their patient had complete resolution of emphysema at 24 hour and was discharged on day two. They followed conservative treatment without any surgical intervention post complication [10].

\section{Conclusion}

With increasing popularity of TEMS for rectal lesion, we expect these kind of complication to occur more frequently. After ruling out rectal perforation by abdominal CT-scan, first conservative management should be done consisting of advanced hemodynamic monitoring and regular follow-up of symptoms\& signs of intestinal perforation and peritonitis so that conservative treatment can be replaced by surgery once the patient deteriorates.

\section{Acknowledgement}

Dr. Kaushal has meticulously followed this patient in the ICU and provided us the follow-up detail.

\section{References}

1. MR Jahadi, A Baldwin Jr (1975) Villous adenomas of the colon and rectum. Am J Surg 130: 729-732.

2. PA Cataldo (2006) Transanal endoscopic microsurgery. Surgical Clinics of North America 86: 915-925.

3. Léonard D, Remue C, Kartheuser A (2012) The transanal endoscopic microsurgery procedure: Standards and extended indications. Dig Dis 2: 85-90.

4. Saclarides TJ, Smith L, K SungTao, Orlan B, Buess G (1992) Trans anal endoscopic microsurgery. Dis Colon Rectum 35: 1183-1191.

5. Gutt CN, Oniu T, Mehrabi A, Schemmer P, Kashfi A, et al. (2004) Circulatory and respiratory complications of carbon dioxide insufflation. Dig Surg 21: 95-105.

6. Bignell MB, Ramwell A, Evans JR, Dastur N, Simson JN, et al. (2010) Complications of transanal endoscopic microsurgery (TEMS): A prospective audit. Colorectal Dis 12: e99-103.

7. Rudston-Brown BC, MacLennan D, Warriner CB, Phang PT (1996) Effect of subcutaneous carbon dioxide insufflation on arterial carbon dioxide. Am J Surg 171: 460-463.

8. Kerr K, Mills GH (2001) Intra-operative and post-operative hypercapnia leading to delayed respiratory failure associated with transanal endoscopic microsurgery under general anaesthesia. Br J Anaesth 86: 586-589.

9. Franken RJ, Moes DE, Acherman YI, Derksen EJ (2012) Free intra-abdominal air without peritoneal perforation after TEM: A report of two cases. Case Rep Surg 2012: 185429.

10. Chandra A, Clarke R, Shawkat $H$ (2014) Intraoperative hypercarbia and massive surgical emphysema secondary to transanal endoscopic microsurgery (TEMS). BMJ Case Rep. 